\title{
Seasonal variation in maternal and umbilical cord 25(OH) vitamin D and their associations with neonatal adiposity
}

\author{
Kristin Godang ${ }^{1}$, Kathrine Frey Frøslie ${ }^{2,3}$, Tore Henriksen ${ }^{4,5}$, Elisabeth Qvigstad ${ }^{1}$ and \\ Jens Bollerslev ${ }^{1,5}$ \\ 'Section of Specialized Endocrinology, Department of Endocrinology, Oslo University Hospital Rikshospitalet, \\ PO Box 4950 Nydalen, 0424 Oslo, Norway, ${ }^{2}$ Department of Biostatistics, Institute of Basic Medical Sciences, \\ University of Oslo, Oslo, Norway, ${ }^{3}$ Norwegian Resource Center for Women's Health, Oslo University Hospital, Oslo, \\ Norway, ${ }^{4}$ Division of Obstetrics and Gynecology, Oslo University Hospital Rikshospitalet, Oslo, Norway and \\ ${ }^{5}$ Faculty of Medicine, University of Oslo, Oslo, Norway
}

\author{
Correspondence \\ should be addressed \\ to K Godang \\ Email \\ kgodang@ous-hf.no
}

\section{Abstract}

Design: Neonatal body fat is an important indicator of foetal energy supply and growth with potential importance for long-term health. In this study, we wanted to explore seasonal variation of 25-hydroxy-vitamin D (25(OH)D) in maternal and umbilical cord plasma (UCP) to examine whether maternal and foetal 25(OH)D levels were associated with maternal $\mathrm{BMI}$ and neonatal fat mass (FM), and to explore the relationship among maternal and neonatal $25(\mathrm{OH}) \mathrm{D}$ levels, maternal glucose/insulin levels and UCP C-peptide.

Methods: An observational, prospective study of determinants of foetal growth and birth weight in healthy pregnant women. Total body composition in 202 newborns was measured by dual-energy X-ray absorptiometry. Circulating levels of biomarkers were assessed in mothers at gestational weeks 14-16 and 30-32 and UCP.

Results: The mean 25(OH)D concentration in UCP was significantly lower than in maternal circulation (31 vs $45 \mathrm{nmol} / \mathrm{l}$, $P<0.001)$. Maternal and UCP 25(OH)D levels varied significantly with season. No significant association between maternal BMI (weeks 14-16) and UCP 25(OH)D concentration was found. We found a strong positive association between maternal 25(OH)D and UCP 25(OH)D $(P<0.001)$. There was no significant linear association between maternal BMI (weeks 14-16) and maternal 25(OH)D. We found no association between maternal 25(OH)D levels and glucose/insulin levels, nor with maternal or UCP 25(OH)D on UCP C-peptide levels. Finally, neonatal total body FM was positively associated with UCP 25(OH)D, $P=0.02$.

Conclusions: We demonstrated seasonal variation in maternal and neonatal 25(OH)D levels at northern latitudes. UCP, but not maternal, 25(OH)D was a significant predictor of neonatal total FM. Maternal BMI and metabolic parameters such as glucose, insulin and UCP C-peptide levels were not associated with 25(OH)D in mothers or offspring.

\section{Introduction}

The pleiotropic effects of 25-hydroxy-vitamin D $(25(\mathrm{OH}) \mathrm{D})$ in relation to foetal development and neonatal body composition have received attention recently $(1,2)$. This interest has largely been driven by the welldocumented relationship between anthropometric characteristics at birth and the future health of the neonates (3). The growth of the human foetus involves an accretion of adipose tissue during the last trimester (4); neonatal body fat is therefore an important indicator of foetal energy supply and growth conditions $(5,6)$, which are of potential importance for long-term outcome and health (7). (c) 2014 European Society of Endocrinology Printed in Great Britain
Published by Bioscientifica Ltd. 
The foetal levels of $25(\mathrm{OH}) \mathrm{D}$ in utero and at birth are dependent on the maternal pool of $25(\mathrm{OH}) \mathrm{D}$ and transplacental transfer. Maternal vitamin D status during pregnancy may influence skeletal development (8) and body composition in the offspring (9) by influencing programming and development of muscle and fat tissue. Countries at northern latitudes, such as Norway, where u.v.-B (UVB) is insufficient during almost half of the year, exhibit seasonal variation in $25(\mathrm{OH}) \mathrm{D}$ levels in the general population and likely pregnant women, with potential consequences for foetal development (10).

Vitamin D is a fat-soluble prohormone that promotes intestinal calcium absorption. Regardless of their source, the vitamin D precursors ergocalciferol $\left(\mathrm{D}_{2}\right)$ and cholecalciferol $\left(\mathrm{D}_{3}\right)$ are transported to the liver and metabolised into the prohormone, 25-dihydroxyvitamin D, and finally activated by 1- $\alpha$ hydroxylase primarily in the kidneys to the biologically active form 1,25-dihydroxyvitamin D $\left(1,25(\mathrm{OH})_{2} \mathrm{D}\right)$. The major circulating form of the vitamin, $25(\mathrm{OH}) \mathrm{D}$, is considered to be the best measure of vitamin D status (11). As the developing foetus does not produce vitamin $\mathrm{D}$ by itself, and the intrauterine and neonatal periods are critical for vitamin D-related effects, the child is dependent on maternal levels and their ability to pass the placental barrier (7). Previous studies have demonstrated not only that maternal vitamin $D$ status is tightly correlated with umbilical cord plasma (UCP) $25(\mathrm{OH}) \mathrm{D}$ concentrations $(12,13,14)$ but also that trans-placental transport is dependent on maternal BMI.

Vitamin D deficiency and low plasma 25(OH)D levels have been epidemiologically associated with a broad range of conditions, including cancer, diabetes, cardiovascular disease, hypertension and pregnancy complications $(15,16,17,18)$. Excess body weight is associated with decreased serum $25(\mathrm{OH}) \mathrm{D}$ concentrations and a high prevalence of vitamin D deficiency $(19,20)$. The reduced bioavailability of the fat-soluble $25(\mathrm{OH}) \mathrm{D}$, which is related to accumulation in body fat, may be the main reason for this association (21). However, the associations among obesity in pregnancy, vitamin $\mathrm{D}$ status and neonatal vitamin $\mathrm{D}$ levels have not been studied extensively, nor has the relationship between vitamin $\mathrm{D}$ status and neonatal adiposity.

Maternal BMI is one of the most consistent determinants of foetal weight, growth and body composition $(6,22)$. Maternal BMI is positively associated with circulating glucose levels. Furthermore, maternal BMI and glucose have been established as independent determinants of large-for-gestational-age newborns and excessive body fat at birth $(23,24)$. Recently, attention has been focused on a potential role for vitamin $\mathrm{D}$ in the maintenance of normal glucose homeostasis in pregnancy. In addition, vitamin $\mathrm{D}$ deficiency has been found to be associated with pancreatic $\beta$-cell dysfunction and insulin resistance in non-pregnant diabetic and nondiabetic populations $(25,26)$. Glucose is the main energy substrate for intrauterine growth (27). UCP levels of C-peptide are used as an index of foetal $\beta$-cell function, rather than insulin levels, because degradation of insulin is increased in the presence of slight haemolysis (28). Thus, foetal size has been correlated with umbilical total insulin, free insulin and C-peptide (29). Moreover, the recent Hyperglycemia and Adverse Pregnancy Outcome (HAPO) Study showed a linear relationship between increasing maternal glucose and UCP C-peptide with birth weight $(23,30)$.

One of the primary roles of vitamin $\mathrm{D}$ is the regulation of calcium and phosphorus absorption and metabolism for bone health. This effect is especially important during pregnancy because adequate vitamin $\mathrm{D}$ concentrations are necessary to ensure appropriate maternal response to the calcium demands of the foetus and neonatal handling of calcium. The relationship between maternal vitamin D and foetal bone development has recently been reviewed (31), but no association between maternal vitamin D levels and neonatal bone mineral content was demonstrated. This observation is in agreement with our recent findings, where we found that neither foetal nor maternal $25(\mathrm{OH}) \mathrm{D}$ seemed to have a major role in bone mass development in the neonates (32).

Our study included samples from a Norwegian prospective cohort study of healthy pregnant women (33). The samples were collected throughout all seasons, and our first aim in this study was to explore the seasonal variations of $25(\mathrm{OH}) \mathrm{D}$ in the maternal and UCP sides of the placenta. Secondly, we wanted to test the hypotheses that maternal and foetal $25(\mathrm{OH}) \mathrm{D}$ levels are associated with the maternal BMI and neonatal percentage and gram total fat mass (FM). Finally, we wanted to explore this relationship by examining maternal and neonatal $25(\mathrm{OH}) \mathrm{D}$ status, maternal glucose and insulin and UCP C-peptide in this cohort.

\section{Subjects and methods}

The study sample was based on a sub-cohort of 202 women from the STORK study: an observational, prospective study of determinants of foetal growth and birth weight in healthy pregnancies for which the details have been published previously $(32,33)$. In short, the STORK cohort 
consists of women of Scandinavian heritage $(n=1031)$, who registered for obstetric care at Oslo University Hospital Rikshospitalet, from 2001 to 2008. Exclusion criteria were multiple pregnancies, known pre-gestational diabetes and severe chronic diseases (lung, cardiac, gastrointestinal or renal).

The women were scheduled for antenatal visits at gestational weeks 14-16 and 30-32. The maternal height (self-reported) was obtained at the first visit, and the weight was measured at each visit. The BMI was calculated as weight $(\mathrm{kg})$ divided by height $\left(\mathrm{m}^{2}\right)$. In the analyses, only the BMI from the first visit was used, as this value was the best estimate for the pre-gestational body composition. Intake of macronutrients, including the total vitamin $\mathrm{D}$ intake (from food or supplements), was calculated. However, as it was not possible to distinguish between the intake from food and supplements, and as there was not a significant association between the estimated vitamin $\mathrm{D}$ intake and maternal $25(\mathrm{OH}) \mathrm{D}$, these data are not shown in the manuscript.

\section{Biochemical variables}

A $75 \mathrm{~g}$ oral glucose tolerance test (OGTT) was performed twice, at gestational weeks $14-16$ and 30-32. During the OGTT, serum samples were obtained every $30 \mathrm{~min}$ for $2 \mathrm{~h}$. Maternal glucose and insulin were measured in the blood and serum samples from the OGTT. Glucose and insulin areas under the curve (AUC) during the OGTT were calculated using the trapezoidal rule. Glucose measurements were performed with an Accu-Chek Sensor glucometer using Accu-Chek glucose test strips (Roche Diagnostics $\mathrm{GmbH}$ ). The glucose was measured immediately in EDTA blood. Serum insulin was analysed by a RIA (DPC, Los Angeles, CA, USA).

The serum samples were collected in $6 \mathrm{ml}$ Vacutainer tubes, centrifuged at room temperature at $2500 \mathrm{~g}$ for $10 \mathrm{~min}$, aliquoted and stored at $-80^{\circ} \mathrm{C}$ until analysed: $4 \mathrm{ml}$ Vacutainer tubes containing EDTA were centrifuged $\left(2500 \mathrm{~g}\right.$ and $4{ }^{\circ} \mathrm{C}$ for $25 \mathrm{~min}$ ) and frozen at $-80^{\circ} \mathrm{C}$, aliquoted and stored at $-80^{\circ} \mathrm{C}$ until analysed. Umbilical cord blood was collected into EDTA tubes by the midwife, centrifuged for plasma separation and placed at $-20^{\circ} \mathrm{C}$ for less than a month and at $-80^{\circ} \mathrm{C}$ for long-term storage.

Maternal circulating levels of 25(OH)D were analysed in samples of gestational weeks 30-32. Measurements of 25(OH)D and C-peptide were performed in the UCP. The plasma levels of $25(\mathrm{OH}) \mathrm{D}$ and $\mathrm{C}$-peptide were measured using a RIA from DiaSorin (MN, USA) and Millipore Corporation (Billerica, Stillwater, MA, USA) respectively.
All assays were performed according to the manufacturer's instructions. The intra- and inter-assay coefficients of variation (CV values) were $<10 \%$ for all assays.

\section{Dual-energy X-ray absorptiometry measurements}

Neonatal body composition was determined by dualenergy X-ray absorptiometry (DXA; GE Lunar Prodigy Densitometer (software version 12.10; GE Medical Systems, Lunar Corp., Madison, WI, USA). All DXA scans were performed within 4 days postpartum. The scanning procedure has been described in detail previously (34). DXA measurements provided information on bone mass, total FM and fat-free mass (FFM). Percentage fat was based on DXA-derived fat minus DXA-derived sum of fat, lean and bone mineral content.

According to the manufacturer, the CV values (\%) for a Lunar DPX-L instrument (regarded by the manufacturers to be similar to the Lunar Prodigy) are 2.0 and $1.1 \%$ for FM and FFM respectively (35).

\section{Ethics}

Written informed consent was obtained from the participants. The study was approved by the Regional Ethics Committee, Southern Norway, and performed according to the Declaration of Helsinki.

\section{Statistical analysis}

Descriptive statistics are means (s.D.) or medians (quartiles). Comparisons of the women and neonates in the study sample and the women and neonates born at term, who were not elected for this study, were performed by independent sample $t$-tests or Mann-Whitney $U$ tests.

The maternal and cord blood seasonal variations in $25(\mathrm{OH}) \mathrm{D}$ were estimated by functional data analysis, using Fourier basis functions (36) to account for cyclic variation. The number of basis functions was chosen based on visual inspection of plots of estimated curves combined with calculations of the corresponding generalised cross-validation criterion (37). Pointwise 95\% CIs were calculated (37).

Univariate and multivariable linear regression analyses were used to estimate the association of maternal BMI with maternal and UCP 25(OH)D, maternal glucose AUC, insulin AUC and C-peptide in cord blood, and neonatal body fat. Regression analyses were also used to estimate the association of maternal and UCP $25(\mathrm{OH}) \mathrm{D}$ levels with maternal glucose AUC, insulin AUC and 
C-peptide in cord blood, and neonatal body fat. Linear regression model assumptions were checked for each analysis separately. A $P$ value $<0.05$ was considered statistically significant.

Except for the analysis of the seasonal variation, which was performed using the fda package in $\mathrm{R}$ 3.0.0 (38), all analyses were performed using SPSS version 18.0 (SPSS, Inc.).

\section{Results}

\section{Demographics for mother and child}

The demographic and clinical details in the study sample are presented in Table 1 . The neonates in the study population were comparable with the neonates in the main cohort regarding birth weight $(3612 \mathrm{~g}$ (480) vs $3670 \mathrm{~g}$ (487); $P=0.13$ ) and gestational age at birth (40.2 week (1.2) vs 40.2 week (1.2); $P=0.90)$. The women in the study sample had a significantly lower BMI, glucose AUC and fasting insulin at gestational weeks 14-16 $(0.001 \leq P \leq 0.13)$ and a lower BMI, fasting glucose and fasting insulin at weeks $30-32(P \leq 0.02)$ than the other eligible women in the STORK cohort.

\section{Seasonal variation in maternal and UCP 25(OH)D concentrations}

The mean $25(\mathrm{OH}) \mathrm{D}$ concentration in UCP was significantly lower than in maternal circulation (31 vs $45 \mathrm{nmol} / \mathrm{l}, \quad P<0.001$; Table 1$)$. The distribution of maternal and UCP $25(\mathrm{OH}) \mathrm{D}$ concentration varied by time of the year is shown in Fig. 1. The pointwise 95\% CIs in Fig. 1 show that the concentration of maternal $25(\mathrm{OH}) \mathrm{D}$ varied significantly by time of the year, with highest levels in the Norwegian summer months (JuneSeptember) and the lowest levels in the winter months (December-March).

The same seasonal variation (relative to month of birth) was found in UCP $25(\mathrm{OH}) \mathrm{D}$, with the highest levels during June-October and the lowest levels during December-April.

\section{Association between maternal BMI and vitamin D levels in mother and child}

No significant association between maternal BMI (weeks 14-16) and UCP 25(OH)D concentration was found (standardised regression coefficient, $\beta=0.10, P=0.23$ ),

Table 1 Sample characteristics of the pregnant women and their infants. Numbers are mean (s.D.) or median $\left(Q_{1}, Q_{3}\right)$.

\begin{tabular}{|c|c|c|c|}
\hline & $\begin{array}{l}\text { Women, } n=202^{a} \\
\quad(\text { weeks 14-16) }\end{array}$ & $\begin{array}{l}\text { Women, } n=202^{a} \\
\quad \text { (weeks 30-32) }\end{array}$ & Infants, $n=202^{\mathrm{a}, \mathrm{b}}$ \\
\hline \multicolumn{4}{|l|}{ Maternal characteristics } \\
\hline BMI $\left(\mathrm{kg} / \mathrm{m}^{2}\right)$ & $23.9(3.8)$ & $26.6(3.8)$ & \\
\hline Obese $\left(\mathrm{BMI}>30 \mathrm{~kg} / \mathrm{m}^{2}\right)$ & $14(7 \%)$ & & \\
\hline Fasting glucose $(\mathrm{mmol} / \mathrm{l})$ & $4.0(0.4)$ & $4.0(0.4)$ & \\
\hline Glucose AUC & $9.3(1.9)$ & $11.9(2.2)$ & \\
\hline Fasting insulin $(\mathrm{pmol} / \mathrm{l})$ & $24(15,34)$ & $37(25,58)$ & \\
\hline Insulin AUC & $408(280,582)$ & $770(565,1022)$ & \\
\hline $25(\mathrm{OH}) \mathrm{D}(\mathrm{nmol} / \mathrm{l})$ & & $45(17)$ & \\
\hline \multicolumn{4}{|l|}{ Infant characteristics } \\
\hline $\begin{array}{l}\text { Gestational age at birth } \\
\text { (weeks) }\end{array}$ & & & $40.2(1.2)$ \\
\hline Birth weight $(g)$ & & & $3612(480)$ \\
\hline C-peptide (ng/ml) & & & $1.1(0.7)$ \\
\hline $25(\mathrm{OH}) \mathrm{D}(\mathrm{nmol} / \mathrm{l})$ & & & $31(18)$ \\
\hline \multicolumn{4}{|l|}{ DXA } \\
\hline Scan day (after birth) & & & $1.8(1.0)$ \\
\hline Scan day weight (g) & & & $3427(460)$ \\
\hline Total body FM (\%) & & & $13.5(2.3)$ \\
\hline Total body FM (g) & & & $498(122)$ \\
\hline $\mathrm{BMC}$ & & & $93(12)$ \\
\hline
\end{tabular}

BMI, body mass index $\left(\mathrm{kg} / \mathrm{m}^{2}\right.$; self-reported); AUC, area under the curve; DXA, dual-energy X-ray absorptiometry; FM, total body fat mass; BMC, total bone mineral content; 25(OH)D, 25-hydroxy-vitamin D. ${ }^{a} n$ may vary due to missing values.

${ }^{\mathrm{b}}$ Born at term, defined as birth at gestational week 37 or later. 


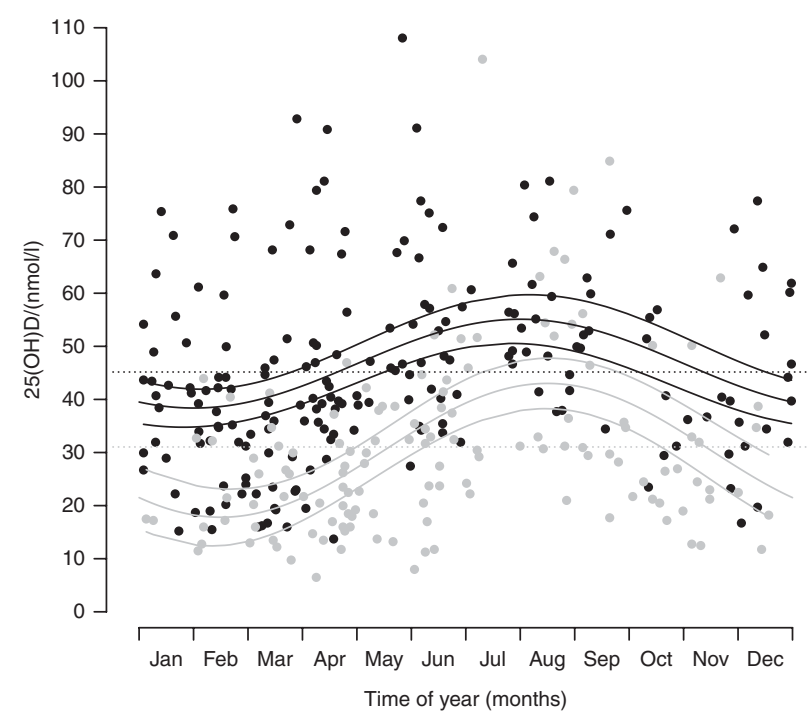

Figure 1

Relations between time of year and 25(OH)D levels. The black dots represent maternal values and the grey dots represent umbilical cord plasma (UCP) of 25-hydroxy-vitamin D [25(OH)D]. The thick black and grey lines are the smoothed estimates of the maternal and UCP concentration of $25(\mathrm{OH}) \mathrm{D}$ respectively.

The thin black and grey lines are the corresponding pointwise $95 \% \mathrm{Cls}$.

but there was a strong positive association between maternal 25(OH)D and UCP 25(OH)D $(\beta=0.42, P<0.001)$.

We found no seasonal variation in maternal BMI or birth weight (data not shown). There was no significant linear association between maternal BMI (weeks 14-16) and maternal $25(\mathrm{OH}) \mathrm{D}(\beta=-0.03, P=0.64)$, but a scatter plot with local regression lines indicated a potential nonlinear association, with the highest maternal 25(OH)D values for women with low BMI (data not shown). To explore this observation further, BMI was dichotomised by the lower BMI quartile (BMI $21.4 \mathrm{~kg} / \mathrm{m}^{2}$ ) and the mean $25(\mathrm{OH}) \mathrm{D}$ levels were compared in the two groups. The difference between the groups was in accordance with the scatter plot regression lines but non-significant, $P=0.07$. We found no association between 25(OH)D levels related to $\mathrm{BMI}$ estimated at the time point corresponding to the vitamin D analyses (weeks 30-32): data not shown.

\section{Association between maternal 25(OH)D levels and maternal glucose and insulin levels, weeks 30-32}

Univariate linear regression analyses showed no significant association between maternal 25(OH)D levels and $\mathrm{AUC}_{\text {glucose }}$ or $\mathrm{AUC}_{\text {insulin }}(\beta=0.06, P=0.38$ and $\beta=-0.01, P=0.86$ respectively). These results remained non-significant $(\beta=0.09, P=0.24$ and $\beta=0.02, P=0.83$ respectively) after adjustment for maternal BMI.

\section{Association between maternal 25(OH)D levels and UCP C-peptide concentration}

There were no significant associations between maternal or UCP $25(\mathrm{OH}) \mathrm{D}$ and UCP C-peptide levels in univariate regression analyses, nor did the result change after adjustment for maternal BMI $(\beta=-0.02, P=0.84$ and $\beta=-0.03, P=0.75$ for maternal and UCP $25(\mathrm{OH}) \mathrm{D}$ respectively).

\section{Association between maternal and UCP 25(OH)D levels and $\mathrm{BMI}$ on neonatal $\mathrm{FM}$ in gram and percentage}

In univariate regression analyses, there was no statistically significant association between maternal $25(\mathrm{OH}) \mathrm{D}$ and neonatal total body FM $(\beta=-0.02, P=0.75)$, but there was a significant association between UCP 25(OH)D and neonatal total body FM $(\beta=0.20, P=0.02)$. Adjustment for BMI gave only minor changes in the estimates: $\beta=-0.04$, $P=0.67$ and $\beta=0.20, P=0.03$ for maternal and UCP $25(\mathrm{OH}) \mathrm{D}$ respectively.

In univariate regression analyses, there was no significant association between maternal 25(OH)D and neonatal percentage fat $(\beta=0.04, P=0.55)$, but a significant association between UCP $25(\mathrm{OH}) \mathrm{D}$ and neonatal percentage fat $(\beta=0.20, P=0.02)$ was found. After adjustment for BMI, the latter estimate was no longer significant. The adjusted estimates were $\beta=0.04, P=0.69$ and $\beta=0.17$, $P=0.07$ for maternal and UCP 25(OH)D respectively.

\section{Discussion}

This study demonstrates seasonal variation in maternal and neonatal 25(OH)D levels, with neonatal levels being approximately two-thirds of the maternal levels. Maternal 25(OH)D levels did not predict neonatal FM, whereas 25(OH)D in UCP was associated with DXA-assessed neonatal total body FM. Finally, maternal BMI, glucose, insulin and UCP C-peptide were not related to maternal or neonatal $25(\mathrm{OH}) \mathrm{D}$ levels. The seasonal variation of $25(\mathrm{OH}) \mathrm{D}$ was assessed from maternal and umbilical cord evenly distributed during the year. Thus, vitamin D status exhibits a strong seasonal variation that parallels the seasonal change in the fluence of solar UVB. Our data are in accordance with a study recently published in Germany (10). 
During winter, the UVB fluence rate in the Nordic countries $\left(50-71^{\circ} \mathrm{N}\right)$ is below the level required for vitamin $\mathrm{D}$ synthesis in skin (39). Our measured seasonal variation of the vitamin $\mathrm{D}$ status is in agreement with results from non-pregnant subjects from other Scandinavian investigations demonstrating a $20-120 \%$ increase in calcidiol levels from winter to summer $(40,41)$. We found maternal and neonatal $25(\mathrm{OH}) \mathrm{D}$ levels with a peak in June through September and with minimum levels during the winter, from December through March. As expected, 25(OH)D levels in maternal and UCP were significantly correlated, but the seasonal peak in UCP seems to have a delay of approximately a month. Furthermore, 25(OH)D levels in the neonates were approximately two-thirds of the maternal levels, which confirms earlier observations $(10,42)$. Vitamin D-binding protein is known to increase slightly during pregnancy (43): however, the magnitude of this increase is not large enough to explain the maternal-foetal difference. The correlation of UCP and maternal $25(\mathrm{OH}) \mathrm{D}$ levels suggests that $25(\mathrm{OH}) \mathrm{D}$ may be the predominant metabolite transferred to the foetus.

The foetal 25(OH)D levels at birth are dependent on the maternal concentration of $25(\mathrm{OH}) \mathrm{D}$ and the placental ability to transfer $25(\mathrm{OH}) \mathrm{D}$. Cord concentrations of the three major vitamin D metabolites are consistently lower than those measured in maternal serum. UCP $25(\mathrm{OH}) \mathrm{D}$ and 24,25-dihydroxyvitamin D concentrations correlate significantly with those found in the maternal circulation, implying that these two secosteroids pass easily across the placental barrier and that the vitamin $D$ pool of the foetus depends entirely on maternal levels (42).

Vitamin D levels are decreased in obesity, possibly because the fat-soluble vitamin is stored in the fat tissue. Obese pregnant women may need larger amounts of vitamin $\mathrm{D}$ supplementation to provide their neonates with sufficient levels of vitamin D (21). In this study, we could not confirm a lower $25(\mathrm{OH}) \mathrm{D}$ level in the women with the higher BMI, nor was there any significant linear association between maternal BMI (weeks 14-16) and maternal 25(OH)D. Moreover, we could not demonstrate a seasonal variation for maternal BMI. These findings are consistent with a recent study (44) demonstrating similar levels of 25(OH)D when measured at 36-38 weeks of pregnancy, irrespective of BMI. Studies in non-pregnant populations have shown a relationship between vitamin D status and body fat $(19,20)$. The weakly indicated nonlinear association between maternal BMI and 25(OH)D, that is, potentially increased plasma $25(\mathrm{OH}) \mathrm{D}$ levels in pregnancy with low BMI, remains to be elucidated, although non-significant in our sample. To some extent, an inverse relationship between vitamin $\mathrm{D}$ and adipocytes may be attributed to the sequestering of vitamin $\mathrm{D}$ in fat stores. In our study sample, low BMI is most likely because of lifestyle factors, such as high education, eating regime or more physical activity.

In our study, we found no significant association between maternal BMI (weeks 14-16) and UCP 25(OH)D levels in contrast to a previous study (44), where maternal obesity was associated with UCP 25(OH)D levels. This study included normal-weight and obese mothers, and both groups had similar maternal 25(OH)D levels irrespective of BMI category. Maternal obesity was presented as a category, and the study showed that UCP $25(\mathrm{OH}) \mathrm{D}$ levels were significantly different in infants born to normal-weight compared with obese mothers. Thus, infants born to obese mothers had lower levels of $25(\mathrm{OH}) \mathrm{D}$ compared with infants born to lean mothers. Our cohort consists predominantly of normal-weight pregnant women (BMI 26.6, weeks 30-32), as only 7\% were categorised as obese (BMI> $30 \mathrm{~kg} / \mathrm{m}^{2}$ ). The small amount of obese may explain the inconsistencies between the studies.

As described previously (32), the mean 25(OH)D concentration in UCP was significantly lower than in maternal circulation. The only source of vitamin D in the neonates is through maternal placental transfer of the nutrient hormone, $25(\mathrm{OH}) \mathrm{D}$. The results indicate that different BMIs in pregnant women result in varying efficiency of the transfer of $25(\mathrm{OH}) \mathrm{D}$ to the neonates, consistent with the theory of reduced bioavailability of vitamin D in obesity (21). The UCP 25(OH)D differences between neonates born to obese and normal-weight women are consistent with a previous paper (45). This study explored the association between prepregnancy BMI and maternal and infant vitamin $\mathrm{D}$ status and found significant differences between prepregnancy obese vs lean mothers. The overweight and obese women when compared with lean women were more likely to have vitamin $\mathrm{D}$ deficiency and to deliver newborns with vitamin D deficiency. Our results without significant association between maternal BMI and UCP 25(OH)D levels can be explained by a more normal-weight distribution.

The relationship among maternal vitamin D status, glucose metabolism and foetal growth is likely to be complex. In our study, maternal BMI and metabolic parameters such as glucose, insulin or UCP C-peptide were not related with maternal or neonatal $25(\mathrm{OH}) \mathrm{D}$ levels. The concentration of $25(\mathrm{OH}) \mathrm{D}$ has been shown to have a positive relationship with insulin sensitivity and a negative effect on $\beta$-cell function (25). However, to our knowledge no report of these associations has been 
shown in the same study. Separate reports have shown the association of decreased vitamin $\mathrm{D}$ with insulin resistance (46) and $\beta$-cell dysfunction (47). In our study, UCP $C$-peptide, which is secreted in equimolar concentrations with insulin, was used as an index of foetal $\beta$-cell function. Our data, when compared with previously published data, indicate that the effect of vitamin $\mathrm{D}$ on $\beta$ cells is more complex. Studies that show correlations among vitamin $\mathrm{D}$, glucose and insulin often include subjects with diabetes, impaired glucose tolerance or impaired fasting glucose. Our cohort was healthy, and the women were normotensive and glucose tolerant.

Neonatal adiposity has been found to be a good indicator of excess energy supply to the foetus. We demonstrated a positive association between UCP 25(OH)D and neonatal total FM. In contrast, an inverse relationship between vitamin $\mathrm{D}$ levels and adiposity has been demonstrated at later age in children, adolescents and adults (48). The fact that total body percentage FM was significantly associated with UCP $25(\mathrm{OH}) \mathrm{D}$ may indicate an association independent of birth weight.

Our finding of a relationship between UCP 25(OH)D and neonatal adiposity is in agreement with a study of DXA-assessed FM in 977 neonates, which concluded that lower maternal vitamin D status may be linked to programmed differences in offspring FM (9). The study (44) also showed that UCP vitamin D was positively associated with neonatal FM. However, in our study, maternal vitamin $\mathrm{D}$ levels were not related to neonatal total body FM or percentage fat. The diverging study results might be related to methods; in the latter study, a non-specific paediatric software for neonatal measurements of body composition was used. We measured with a specific infant software programme (34) that increases the sensitivity and specificity of the measured FM and FFM. Thus, our results should give more valid measurements of FM and FFM. Our results are consistent with a recent study, in which maternal vitamin D status in late pregnancy was not related to neonatal DXA-assessed FM (49).

The few randomised controlled trials of vitamin D supplements in pregnant women suggest that supplementation may lead to an increase in birth weight (50); however, these results are controversial (51).

The strengths of the STORK study are the wellcharacterised cohort and the prospective design. Secondly, DXA-assessed neonatal total body FM was analysed using infant-specific software.

Potential limitations of our report are the nature of UCP samples, which are a mixture of venous and arterial blood, which makes any conclusion about the direct sources of
C-peptide or 25(OH)D at the foetal site difficult. The present work included several research questions, and consequently several analyses of relations between variables within the same study sample. Because of correlations between variables, it is difficult to apply a formal adjustment for multiple comparisons. $P$ value would be non-significant after any adjustment, and the only result that might be affected by this is the association between UCP $25(\mathrm{OH}) \mathrm{D}$ and neonatal total body FM $(\beta=0.20, P=0.02)$. However, because of the considerations mentioned earlier, we have presented unadjusted results. Our vitamin D assay could not distinguish between $\mathrm{D}_{2}$ and $\mathrm{D}_{3}$ molecular form and measures total $25(\mathrm{OH}) \mathrm{D}\left(\mathrm{D}_{2}+\mathrm{D}_{3}\right)$ and report a total 25(OH)D concentration. Liquid chromatography-tandem mass spectrometry measures all vitamin D metabolites separately and can be selected as the nominal 'gold standard method' for 25(OH)D analysis for the future. Pregnancy is associated with increased levels of vitamin-D-binding protein, as well as $1,25(\mathrm{OH})_{2} \mathrm{D}$ concentration, so this can have an influence on our results. Furthermore, maternal levels obtained in weeks $30-32$ could have changed during the following weeks of pregnancy.

\section{In conclusion}

We demonstrated seasonal variation in maternal and neonatal 25(OH)D levels at northern latitudes. The neonatal 25(OH)D levels were consistently lower than maternal levels. UCP 25(OH)D levels were a significant predictor of neonatal adiposity, whereas maternal 25(OH)D levels did not predict neonatal FM. No associations between maternal BMI and metabolic parameters such as glucose, insulin or UCP C-peptide and maternal or neonatal 25(OH)D levels were found.

\section{Declaration of interest}

The authors declare that there is no conflict of interest that could be perceived as prejudicing the impartiality of the research reported.

\section{Funding}

Funding was obtained from the University of Oslo, thematic research area: Perinatal Nutrition and National Resource Center for Women's Health and Oslo Diabetes Research Center.

\footnotetext{
References

1 Carberry AE, Raynes-Greenow CH, Turner RM, Askie LM \& Jeffery HE. Is body fat percentage a better measure of undernutrition in newborns than birth weight percentiles? Pediatric Research $2013 \mathbf{7 4}$ 730-736. (doi:10.1038/pr)
} 
2 Carberry AE, Raynes-Greenow CH, Turner RM \& Jeffery HE. Customized versus population-based birth weight charts for the detection of neonatal growth and perinatal morbidity in a cross-sectional study of term neonates. American Journal of Epidemiology 2013178 1301-1308. (doi:10.1093/aje/kwt176)

3 Godfrey KM \& Barker DJ. Fetal nutrition and adult disease. American Journal of Clinical Nutrition 200071 1344S-1352S.

4 Herrera E \& Amusquivar E. Lipid metabolism in the fetus and the newborn. Diabetes/Metabolism Research and Reviews 200016 202-210. (doi:10.1002/1520-7560(200005/06)16:3 <202::AID-DMRR116> 3.0.CO;2-)

5 Catalano PM, Thomas A, Huston-Presley L \& Amini SB. Increased fetal adiposity: a very sensitive marker of abnormal in utero development. American Journal of Obstetrics and Gynaecology 2003189 1698-1704. (doi:10.1016/S0002-9378(03)00828-7)

6 Sewell MF, Huston-Presley L, Super DM \& Catalano P. Increased neonatal fat mass, not lean body mass, is associated with maternal obesity. American Journal of Obstetrics and Gynecology 2006195 1100-1103. (doi:10.1016/j.ajog.2006.06.014)

7 Barker DJ. The developmental origins of adult disease. Journal of the American College of Nutrition 200423 588S-595S. (doi:10.1080/ 07315724.2004.10719428)

8 Sayers A \& Tobias JH. Estimated maternal ultraviolet B exposure levels in pregnancy influence skeletal development of the child. Journal of Clinical Endocrinology and Metabolism 200994 765-771. (doi:10.1210/ jc.2008-2146)

9 Crozier SR, Harvey NC, Inskip HM, Godfrey KM, Cooper C \& Robinson SM. Maternal vitamin D status in pregnancy is associated with adiposity in the offspring: findings from the Southampton Women's Survey. American Journal of Clinical Nutrition 201296 57-63. (doi:10.3945/ajcn.112.037473)

10 Weisse K, Winkler S, Hirche F, Herberth G, Hinz D, Bauer M, Roder S, Rolle-Kampczyk U, von BM, Olek S et al. Maternal and newborn vitamin D status and its impact on food allergy development in the German LINA cohort study. Allergy 201368 220-228. (doi:10.1111/all.12081)

11 Brouwer-Brolsma EM, Bischoff-Ferrari HA, Bouillon R, Feskens EJ, Gallagher CJ, Hypponen E, Llewellyn DJ, Stoecklin E, Dierkes J, Kies AK et al. Vitamin D: do we get enough?: a discussion between vitamin D experts in order to make a step towards the harmonisation of dietary reference intakes for vitamin D across Europe. Osteoporosis International 201324 1567-1577. (doi:10.1007/s00198-012-2231-3)

12 Greer FR. 25-Hydroxyvitamin D: functional outcomes in infants and young children. American Journal of Clinical Nutrition $2008 \mathbf{8 8}$ 529S-533S.

13 Lee JM, Smith JR, Philipp BL, Chen TC, Mathieu J \& Holick MF. Vitamin D deficiency in a healthy group of mothers and newborn infants. Clinical Pediatrics 200746 42-44. (doi:10.1177/0009922806289311)

14 Markestad T, Aksnes L, Ulstein M \& Aarskog D. 25-Hydroxyvitamin D and 1,25-dihydroxyvitamin D of D2 and D3 origin in maternal and umbilical cord serum after vitamin D2 supplementation in human pregnancy. American Journal of Clinical Nutrition 198440 1057-1063.

15 Grant WB \& Holick MF. Benefits and requirements of vitamin D for optimal health: a review. Alternative Medicine Review 2005 10 94-111.

16 Poel YH, Hummel P, Lips P, Stam F, van der PT \& Simsek S. Vitamin D and gestational diabetes: a systematic review and meta-analysis. European Journal of Internal Medicine 201223 465-469. (doi:10.1016/ j.ejim.2012.01.007)

17 Sorensen IM, Joner G, Jenum PA, Eskild A, Torjesen PA \& Stene LC. Maternal serum levels of 25-hydroxy-vitamin D during pregnancy and risk of type 1 diabetes in the offspring. Diabetes 2012 61 175-178. (doi:10.2337/db11-0875)

18 Thorp JM, Camargo CA, McGee PL, Harper M, Klebanoff MA, Sorokin Y, Varner MW, Wapner RJ, Caritis SN, Iams JD et al. Vitamin D status and recurrent preterm birth: a nested case-control study in high-risk women. BJOG: an International Journal of Obstetrics and Gynecology 2012 119 1617-1623. (doi:10.1111/j.1471-0528.2012.03495.x)
19 Lagunova Z, Porojnicu AC, Lindberg F, Hexeberg S \& Moan J. The dependency of vitamin D status on body mass index, gender, age and season. Anticancer Research 200929 3713-3720.

20 Moan J, Lagunova Z, Lindberg FA \& Porojnicu AC. Seasonal variation of 1,25-dihydroxyvitamin $\mathrm{D}$ and its association with body mass index and age. Journal of Steroid Biochemistry and Molecular Biology 2009113 217-221. (doi:10.1016/j.jsbmb.2009.01.001)

21 Wortsman J, Matsuoka LY, Chen TC, Lu Z \& Holick MF. Decreased bioavailability of vitamin D in obesity. American Journal of Clinical Nutrition 200072 690-693.

22 Roland MC, Friis CM, Voldner N, Godang K, Bollerslev J, Haugen G \& Henriksen T. Fetal growth versus birthweight: the role of placenta versus other determinants. PLoS ONE 20127 e39324. (doi:10.1371/ journal.pone.0039324)

23 Metzger BE, Persson B, Lowe LP, Dyer AR, Cruickshank JK, Deerochanawong C, Halliday HL, Hennis AJ, Liley H, Ng PC et al. Hyperglycemia and adverse pregnancy outcome study: neonatal glycemia. Pediatrics 2010126 e1545-e1552. (doi:10.1542/peds. 2009-2257)

24 HAPO Study Cooperative Research Group. Hyperglycaemia and Adverse Pregnancy Outcome (HAPO) Study: associations with maternal body mass index. BJOG: an International Journal of Obstetrics and Gynecology 2010117 575-584. (doi:10.1111/j.1471-0528.2009.02486.x)

25 Chiu KC, Chu A, Go VL \& Saad MF. Hypovitaminosis D is associated with insulin resistance and $\beta$ cell dysfunction. American Journal of Clinical Nutrition 200479 820-825.

26 Pittas AG \& Dawson-Hughes B. Vitamin D and diabetes. Journal of Steroid Biochemistry and Molecular Biology 2010121 425-429. (doi:10.1016/j.jsbmb.2010.03.042)

27 Clapp JF III. Maternal carbohydrate intake and pregnancy outcome. Proceedings of the Nutrition Society 200261 45-50. (doi:10.1079/ PNS2001129)

28 O'Rahilly S, Burnett MA, Smith RF, Darley JH \& Turner RC. Haemolysis affects insulin but not C-peptide immunoassay. Diabetologia 198730 394-396. (doi:10.1007/BF00292540)

29 Schwartz R, Gruppuso PA, Petzold K, Brambilla D, Hiilesmaa V \& Teramo KA. Hyperinsulinemia and macrosomia in the fetus of the diabetic mother. Diabetes Care 199417 640-648. (doi:10.2337/ diacare.17.7.640)

30 Metzger BE, Lowe LP, Dyer AR, Trimble ER, Chaovarindr U, Coustan DR, Hadden DR, McCance DR, Hod M, McIntyre HD et al. Hyperglycemia and adverse pregnancy outcomes. New England Journal of Medicine 2008358 1991-2002. (doi:10.1056/ NEJMoa0707943)

31 Specker B. Vitamin D requirements during pregnancy. American Journal of Clinical Nutrition 200480 1740S-1747S.

32 Godang K, Froslie KF, Henriksen T, Isaksen GA, Voldner N, Lekva T, Ueland T \& Bollerslev J. Umbilical cord levels of sclerostin, placental weight, and birth weight are predictors of total bone mineral content in neonates. European Journal of Endocrinology 2013168 371-378. (doi:10.1530/EJE-12-0531)

33 Voldner N, Froslie KF, Bo K, Haakstad L, Hoff C, Godang K, Bollerslev J $\&$ Henriksen T. Modifiable determinants of fetal macrosomia: role of lifestyle-related factors. Acta Obstetrica et Gynecologica Scandinavica 2008 87 423-429. (doi:10.1080/00016340801989825)

34 Godang K, Qvigstad E, Voldner N, Isaksen GA, Froslie KF, Notthellen J, Henriksen T \& Bollerslev J. Assessing body composition in healthy newborn infants: reliability of dual-energy $\mathrm{x}$-ray absorptiometry. Journal of Clinical Densitometry 201013 151-160. (doi:10.1016/ j.jocd.2010.01.121)

35 Gately PJ, Radley D, Cooke CB, Carroll S, Oldroyd B, Truscott JG, Coward WA \& Wright A. Comparison of body composition methods in overweight and obese children. Journal of Applied Physiology 200395 2039-2046.

36 Ramsay JO. Functional data analysis. Available at: www.functionaldata.org. 
37 Ramsay JO, Hooker G \& Gray J. Functional Data Analysis with R and MATLAB New York: Springer, 2009.

38 The $\mathrm{R}$ foundation for statistical computing: $\mathrm{R}$ version 3.0.2 (September 25, 2013). Available at: http://www.r-project.org/.

39 Webb AR, Kline L \& Holick MF. Influence of season and latitude on the cutaneous synthesis of vitamin D3: exposure to winter sunlight in Boston and Edmonton will not promote vitamin D3 synthesis in human skin. Journal of Clinical Endocrinology and Metabolism 198867 373-378. (doi:10.1210/jcem-67-2-373)

40 Brustad M, Alsaker E, Engelsen O, Aksnes L \& Lund E. Vitamin D status of middle-aged women at 65-71 degrees $\mathrm{N}$ in relation to dietary intake and exposure to ultraviolet radiation. Public Health Nutrition 20047 327-335.

41 Porojnicu AC, Robsahm TE, Dahlback A, Berg JP, Christiani D, Bruland OS \& Moan J. Seasonal and geographical variations in lung cancer prognosis in Norway. Does vitamin D from the sun play a role? Lung Cancer 200755 263-270. (doi:10.1016/j.lungcan.2006.11.013)

42 Salle BL, Delvin EE, Lapillonne A, Bishop NJ \& Glorieux FH. Perinatal metabolism of vitamin D. American Journal of Clinical Nutrition $2000 \mathbf{7 1}$ 1317S-1324S.

43 Brannon PM \& Picciano MF. Vitamin D in pregnancy and lactation in humans. Annual Review of Nutrition 201131 89-115. (doi:10.1146/ annurev.nutr.012809.104807)

44 Josefson JL, Feinglass J, Rademaker AW, Metzger BE, Zeiss DM, Price HE \& Langman CB. Maternal obesity and vitamin D sufficiency are associated with cord blood vitamin D insufficiency. Journal of Clinical Endocrinology and Metabolism 201398 114-119. (doi:10.1210/ jc.2012-2882)
45 Bodnar LM, Catov JM, Roberts JM \& Simhan HN. Prepregnancy obesity predicts poor vitamin D status in mothers and their neonates. Journal of Nutrition 2007137 2437-2442.

46 Lind L, Hanni A, Lithell H, Hvarfner A, Sorensen OH \& Ljunghall S. Vitamin D is related to blood pressure and other cardiovascular risk factors in middle-aged men. American Journal of Hypertension $1995 \mathbf{8}$ 894-901. (doi:10.1016/0895-7061(95)00154-H)

47 Boucher BJ, Mannan N, Noonan K, Hales CN \& Evans SJ. Glucose intolerance and impairment of insulin secretion in relation to vitamin D deficiency in east London Asians. Diabetologia 199538 1239-1245. (doi:10.1007/BF00422375)

48 Lenders CM, Feldman HA, Von SE, Merewood A, Sweeney C, Wilson DM, Lee PD, Abrams SH, Gitelman SE, Wertz MS et al. Relation of body fat indexes to vitamin D status and deficiency among obese adolescents. American Journal of Clinical Nutrition 200990 459-467. (doi:10.3945/ajcn.2008.27275)

49 Gale CR, Robinson SM, Harvey NC, Javaid MK, Jiang B, Martyn CN, Godfrey KM \& Cooper C. Maternal vitamin D status during pregnancy and child outcomes. European Journal of Clinical Nutrition 200862 68-77. (doi:10.1038/sj.ejcn.1602680)

50 Brooke OG, Brown IR, Bone CD, Carter ND, Cleeve HJ, Maxwell JD, Robinson VP \& Winder SM. Vitamin D supplements in pregnant Asian women: effects on calcium status and fetal growth. BMJ $1980 \mathbf{2 8 0}$ 751-754. (doi:10.1136/bmj.280.6216.751)

51 Mannion CA, Gray-Donald K \& Koski KG. Association of low intake of milk and vitamin D during pregnancy with decreased birth weight. CMAJ: Canadian Medical Association Journal 2006174 1273-1277. (doi:10.1503/cmaj.1041388)

Received 16 October 2013

Revised version received 15 January 2014

Accepted 21 January 2014 